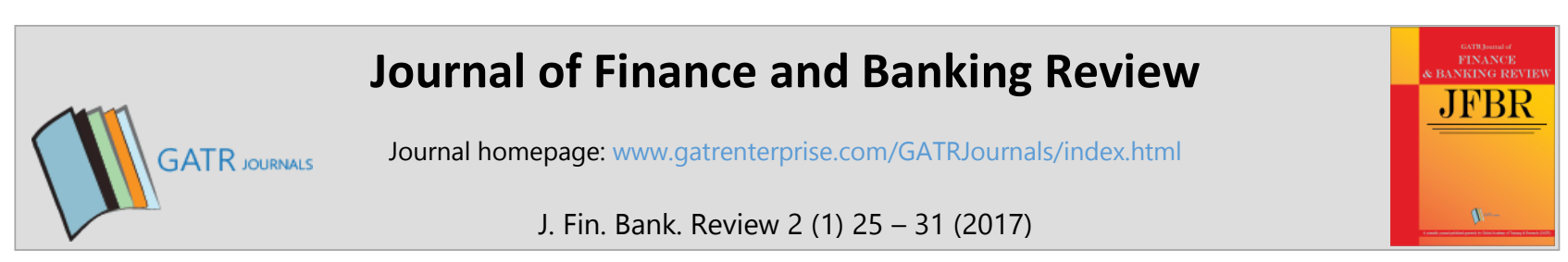

\title{
Black Gold Has Fallen - No More Gambling on the Prices
}

\author{
Yanuar Andrianto ${ }^{1 *}$ and Teuku Fahri Rais Oebit ${ }^{2}$ \\ ${ }^{1,2}$ PPM School of Management, Jl. Menteng Raya 9, 10340, Jakarta, Indonesia
}

\begin{abstract}
Objective - The crude oil, also known as black gold, is an essential commodity for the sustainability of various industries in the world. Oil prices play an important role in world economy because it causes repercussions. For example, world oil prices plummeted at the end of 2013 and its impact created fluctuations in prices which had affected world economy badly. The aim of this research is to locate a good model that can help to predict oil price fluctuations so that industries can avoid potential negative impacts.

Methodology/Technique - Data of world oil prices from 1987 to 2016 were extracted from West Texas Intermediate (WTI) and Brent Oil sources. A comparative analysis using Empirical Decomposition and Autoregressive Integrated Moving Average (ARIMA) was applied to identify differences and data were then analysed through SPSS 23. For this research, a set of models based on the smallest MAPE (Mean Absolute Percentage Error) was proposed.

Findings - Results indicate that the Empirical Decomposition was a more appropriate method for predicting oil prices due to the non-linearity of oil price data. In addition, the MAPE also produced a lower error rate than the ARIMA.

Novelty - In this research, world oil price volatility from West Texas Intermediate (WTI) and Brent Oil Price data were examined to predict oil price movement for future anticipations.
\end{abstract}

Type of Paper: Empirical

Keywords: Forecasting, Oil Prices, Autoregressive Integrated Moving Average, ARIMA, Empirical Decomposition, West Texas Intermediate, Brent Oil Price.

JEL Classification: Q41, Q43.

\section{Introduction}

Oil industry is important and it has impact on the world's economy. Nonetheless, from the perspective of manufacturers, a crisis in the oil industry can create repercussions as can be seen in the last few years, where prices of oil have been showing a very drastic decline (Bloomberg, 2016). In the Petrodollars Countries, oil is a component that has a high rate of selling within the community. In this regard, the global impact of this downward trend fluctuation of oil prices can be serious for some countries and some worldwide industries. The impact these industries get from the price fluctuations is in the form of profits being reduced and massive layoffs. Other countries also experienced a situation where their primary profit sources are ruined.

\footnotetext{
* Paper Info: Received: February 8, 2017

Accepted: March 27, 2017

* Corresponding author:

E-mail: YNR@ppm-manajemen.ac.id

Affiliation: PPM School of Management, Indonesia.
} 
Fluctuations in oil prices not only impact on countries but industries and particular sectors of the industry. For example, daily fluctuations can affect the abundance of price changes not only the price of the fuel itself but also other goods and services which are manufactured. In 1998, the oil price crisis had created problems of budget deficits on oil producer and exporter countries.

The world oil price movement is influenced by many factors (Storm \& Pescatori, 2014; World Bank, 2015). Historically, oil prices are hereditary as can be seen in the occurrences from 1987 up to 2016 . The element that is most influential in affecting price change was identified from the analysis of data drawn from the West Texas Intermediate (WTI) and Brent oil price. The analysis indicated that these occurrences share a commonality i.e., they are seasonal in nature and have a dominating trend.

This research aims to provide a model that can be used to improve the projection of oil prices. The outcome can benefit oil producers as well as oil consumers. There are several previous studies (Al Kharis, 2014) which have attempted to study how oil prices can be predicted and these studies tend to apply two research methods of Empirical Decomposition method and the ARIMA (Autoregressieve Integrated Moving Average) method. The current research will also apply the same.

The Empirical Decomposition method is used as there are elements which dominate world oil prices that are seasonal and in trend. This is because the Empirical Decomposition method has a lower error in predictng world oil price. This is followed by one of the methods that can accommodate the nature of the oil prices. Although the ARIMA is good, it will only be beneficial for short-term data. In this research, the ARIMA is used despite its limitation even though it cannot accommodate the nature of the price of oil itself. This is because the presence of the differentiation stage can transform the nature of the data which is the price of oil itself. In this research, the world oil price volatility from WTI and Brent Oil Price data were examined to predict price movement of future prices. Time series data were used (from 1987 to 2016) to view the price pattern.

\section{Literature Review}

\subsection{World's Oil Price}

According to Horngen, Flat, and Rajan (2012), three factors influence decision making which shapes prices. These factors are the customers, competitors, and also cost. The customer's demand and the supply offered by manufacturers and competitors in the same market raises the equilibrium point, at which the amount of demand and supply of similar products corresponds to the resulting prices. A greater demand will be reflected in the lower prices and greater prices determine the lesser demands that occur.

World oil is also commonly referred to as black gold and it is a much-needed energy. World oil prices affect the actual demand and supply within the world. Three main factors affect price volatility. Fisrt, over supply from producing countries. The Organization of the Petroleum Exporting Countries (OPEC) as the union of oil producing countries inside and outside OPEC, could create an Over-Production which can result in an unbalanced demand and supply. Second, world oil needs within the world is currently on the decrease because of technological developments that have made fuel usage more efficient and the materials processing oil to be less attractive. Third, the United States has other oil products derived from rock called Shale Oil where the oil produced has the same functionality and content of crude oil. it can even be processed into a better substance than the existing crude oil produced by OPEC. Moreover, its cost is cheaper.

In looking at another perspective, it appears that unit prices used in transactions and the determination of oil prices are transacted through the U.S. Dollars (US \$) for per Barrel Oil unit. In this regard, price volatility that happened will be very influential in various fields, not only in mining but also in other sectors such as economy. Commodity prices are the core areas where prices seem to be changing very rapidly, especially in the field of petroleum. This pattern of change in commodity prices is not unique for almost all commodities experience a similar incident when oil price fluctuates, as seen in the last two decades. According to Witjaksono (2010), rising oil prices in general, will encourage a rise in the share prices of the mining sector. 
It was then concluded that the price of oil is able to destroy or strengthen a country. Solutions that can be performed for the oil industry were identified by the Hedging Forward Contracts. It recommended creating an official agreement between two parties in a transaction of a product or asset for the future by determining the cost in advanced; this cost price is determined based on the current situation (Ross, Westerfield, Lim \& Tan, 2012).

\subsection{Previous Research}

There are some studies that have attempted to look at oil price forecasting. Herawati and Djunaidy (2014) had conducted one under the title of "The crude oil price forecasting using a combination of Empirical Mode Decomposition method of Ensemble (EEMD) and Neural Networks". Their results indicate that the volatility of world oil prices would occur more accurately by using the EEMD-JTS instead of the EMD-JTS. Another researcher, Al-Kharis (2014) used the ARIMA and the Decomposition method to forecast the newly formed student enrollment. It was found that the Decomposition method had a better accuracy than the ARIMA in terms of revealing the the resulting MAPE.

Loukazevits (2011) conducted a short term forecasting of crude oil prices by using the HAM (Heterogeneous Agents Models) method. A comparison of the accuracy of forecasting methods between the HAM and Random Walk Models showed both symmetrical and asymmetrical features. Behmiri and Manso (2013) also conducted a study of crude oil price forecasting techniques by making a comprehensive review of literature. It was found that forecasting world oil prices techniques can be divided into two methods: qualitative and quantitative. Quantitative methods are further divided into econometric methods (time-series models, financial models, structural models, and standard or non-standard approach to computational methods).

\subsection{Theoretical Framework}

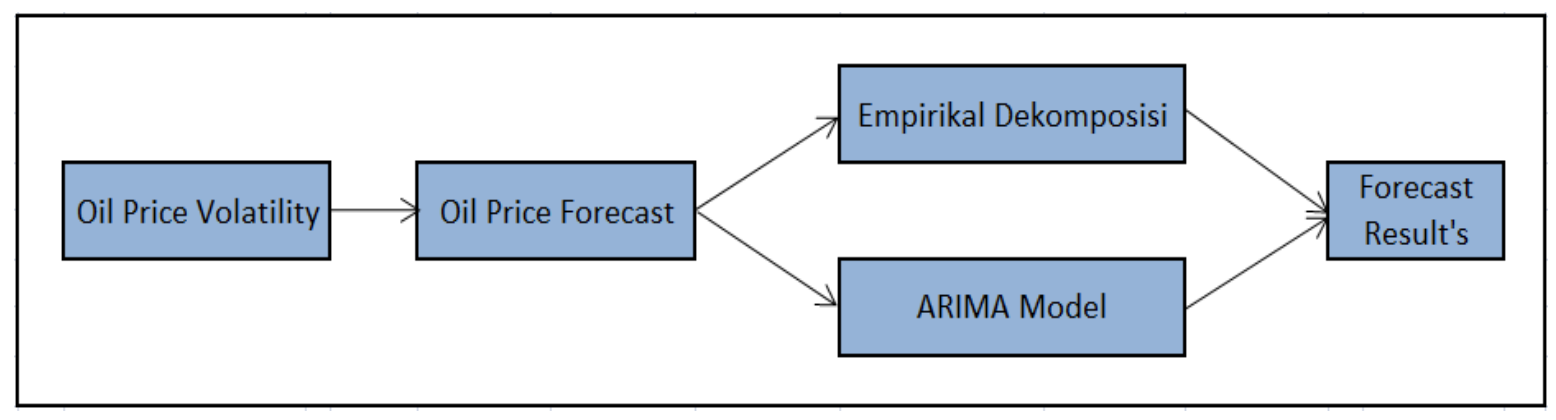

Figure 1. Theoretical Research Framework

Source: Processed Data, Andrianto \& Oebit (2016)

Figure 1 illustrates how solutions for world oil price volatility were derived. Based on the previous studies, the ARIMA and Empirical Decomposition were used to predict world oil prices. Several models were used to accommodate oil price rapid movement and to measure these volatility and finding the best precision. The outcome of these studies indicate that world oil price forecasting can be done with historical or actual data through the comparison of these two methods. Thus, it can be said that these two methods can be used in the future to prevent the impact of oil price fluctuations caused by the world's oil price volatility.

\section{Research Methodology}

The aim of this research is to see how world oil prices change. The sample used in this research are world oil price data which were collected from May 1987 to February 2016. The Black Gold data for the current research were extracted from the West Texas Intermediate (WTI) and Brent Oil Price sources. The wideranging historical data were used to design a prediction model that has minimum bias for the god of better 
prediction accuracy. The independent variable used is the oil price volatility while the dependent variable used is the price forecast (Figure 1).

Data were analysed through the Statistical Program for Social Science (SPSS) version 23 for the purpose of determining oil price forecast accuracy. Data were analyzed by comparing the results drawn from the two methods used: the ARIMA (autoregressive moving average) and the Empirical Decomposition (ED) methods. The comparison between both can help to determine which method has better accuracy in predicting world oil prices. This research is a continuation of the research conducted by Sharma (1998) and Herawati and Djunaidy (2014) in terms of predicting world oil prices.

The Empirical Decomposition was used for analyzing the monthly data which amounted to as much as 346 items. According to Subagyo (1986), this method is based on the premise that what happened normally in the past is likely to happen again in the future in the same pattern. Changes to a pattern is likely to be followed by complex elements such as growth or increase, fluctuations and irregularity. This method will make it easier for the analysis to be broken down into four patterns i.e. Trend (T), (M) seasonal fluctuations, fluctuation cycle $(\mathrm{S})$, and the changes which are random or Random Error $(R / E)$. Each of these components will be processed one by one and they will then be merged back into one value that is then used to estimate or forecast prices. The Decomposition method is divided into two models namely, the decomposition of the additive and the decomposition of the multiplicative. The decomposition of the additive model is a method that forecasts by summing the projection as a result of forecasting (all components added to get the forecast) as the following illustrates:

$$
Y=f(T x+M x+S x+R x)
$$

where the multiplicative is a model of divination by multiplied windows which will arise as a result of forecasting (all components are multiplied to get the forecast) as is illustrated by the following:

$$
Y=f(T x * M x * S x * R x)
$$

The second method, the ARIMA is more reliable for short term-forecasting. It usually shows a flat tendency (constant) for a long term. This method uses previous data and present data of the dependent variable to generate an accurate short-term forecasting. This method has three basic stages i.e. identification, assessment and testing prior to diagnostic examinations. Hendranata (2003) notes that the ARIMA is divided into 3 groups, namely model autoregressive (AR), the moving average (MA), and a mixed model of the ARIMA (autoregressive moving average) which combines the characteristics of the two models. This is applied in the current research.

\section{Findings}

The Empirical Decomposition method is a projection of business patterns data that are grouped into four main components namely Trend (T), Seasonal (M), cycle (S), and Error (E). Oil price projections are based on the four main components in a separate manner. After the processing of data is done through the Empirical decomposition method, it was found that results can be expressed quantitatively in the following explanation:

Table 1. Comparisons of Error: Additives and Multiplicative

\begin{tabular}{|c|c|c|}
\hline Empirical Decomposition & World's Oil Price & MAPE \\
\hline \multirow{2}{*}{ Additive } & WTI & $3.001 \%$ \\
\cline { 2 - 3 } & Brent & $3.301 \%$ \\
\hline \multirow{2}{*}{ Multiplicative } & WTI & $3.452 \%$ \\
\cline { 2 - 3 } & Brent & $3.662 \%$ \\
\hline
\end{tabular}

Source: Processed Data, Andrianto \& Oebit (2016) 
Table 1 indicates that the additive decomposition model has a better prediction than the decomposition of multiplicative model. When viewed from the total error, the results noted from each projections performed showed that the average MAPE formed was of 3.354\%.

The WTI and Brent data were processed so as to determine the ARIMA models in predicting world oil price. Three ARIMA models were formed: ARIMA $(1,1,0)$, ARIMA $(0,1,1)$, and ARIMA $(1,1,1)$. Data processing through SPSS 23 developed the analysis of forecasting time series as well as the autocorrelations.

The models were formed by comparing the error in the Diagnostic Checking. Error used in the comparisons of the MAPE was likened to the analysis done before i.e. business projection method analysis of Empirical Decomposition. The following error for the MAPE was generated by each model:

Table 2. Comparisons of MAPE

\begin{tabular}{|l|l|l|l|}
\hline ARIMA Model & $(0,1,1)$ & $(1,1,0)$ & $(1,1,1)$ \\
\hline MAPE & $6.436 \%$ & $6.503 \%$ & $6.508 \%$ \\
\hline
\end{tabular}

Source: Processed Data Andrianto \& Oebit (2016)

Based on Table 2, it can be seen that the ARIMA model $(0,1,1)$ has the smallest MAPE Error. In this regard, it has better accuracy than the other models. The average error in the ARIMA Model was noted as $6.482 \%$.

From Table 3, it appears that the results of this research indicate that both forecasting methods can perform, but the results and accuracy were different. According to the nature of the data (nonlinear and non-stationary), Empirical Decomposition is a more suitable and reliable method. The following table shows the result of the comparison of the resulting error in describing the accuracy of the two forecasting methods.

Table 3. Comparison MAPE Empirical Decomposition and ARIMA

\begin{tabular}{|c|c|c|c|}
\hline \multicolumn{2}{|c|}{ Methods } & World's Oil Price & MAPE \\
\hline \multirow{3}{*}{$\begin{array}{c}\text { Empirical } \\
\text { Decomposition }\end{array}$} & \multirow{2}{*}{ Additive } & WTI & $3.001 \%$ \\
\cline { 2 - 4 } & & Brent & $3.301 \%$ \\
\cline { 2 - 2 } & \multirow{2}{*}{ Multiplicative } & WTI & $3.452 \%$ \\
\cline { 2 - 2 } & & Brent & $3.662 \%$ \\
\hline \multirow{3}{*}{ ARIMA } & $(0,1,1)$ & \multirow{2}{*}{ WTI \& Brent } & $6.436 \%$ \\
\cline { 2 - 2 } & $(1,1,0)$ & & $6.503 \%$ \\
\cline { 2 - 4 } & $(1,1,1)$ & & $6.508 \%$ \\
\hline
\end{tabular}

Source: Processed Data, Andrianto \& Oebit (2016)

\section{Discussion}

The results from the ARIMA Model had the same growth, with constant prices of black gold. This is because the ARIMA Model requires data that are stationary. While forecasting for long-range accuracy, it produces less good results which tend to be ordinarily flat (constant) for quite long periods. This was supported by Hendrawan (2013). In addition, the results also support the outcome noted in a previous study conducted by Al-Kharis (2014). Consequently, it was noted that the Decomposition and ARIMA methods produced results similar to the decomposition of the additive has the smallest error.

The results of the projections are appropriate methods with the smallest error. Additive Decomposition shows that 2017 will be the turning point of the oil price crisis which had occurred in the last few years. The results noted in this research was supported by some news from trusted sources stating that the main factor in the decline in prices occurred due to an oversupply. 
Table 4. Comparisons of Actual Price and Yield Forecast

\begin{tabular}{|l|l|l|l|l|}
\hline \multicolumn{1}{|c|}{ Dates } & \multicolumn{2}{c|}{ Actual } & \multicolumn{2}{c|}{ Forecast } \\
\hline & \multicolumn{1}{|c|}{ WTI } & Brent & WTI & Brent \\
\hline March 2016 & 37.55 & 38.21 & 33.54 & 33.52 \\
\hline April 2016 & 40.75 & 41.58 & 35.88 & 35.53 \\
\hline
\end{tabular}

Source: Data Processed, Andrianto \& Oebit (2016)

Based on the comparison of data above (Table 4), it can be seen that error compared with the actual price in March 2016 for the price of WTI and Brent was 10.67\% and 12,77\% respectively. For April, the error that was formed at the price of WTI and Brent was $11.95 \%$ and $14,55 \%$ respectively. Although the value of the tolerance of $10 \%$, the price of the results forecast a $12.36 \%$ average error. This means that the result of the visible price forecast is larger than the value of tolerance. To minimize the error between the actual price, other advanced methods can be combined.

The results further show that the MAPE of the Empirical Decomposition method is better than the ARIMA. While world oil price forecasting methods are intended to accommodate the nature of crude oil prices as it tends to be nonlinear and nonstationary, and is influenced by many factors, the method that integrates the Empirical Decomposition and the Neural Network are helpful and better in predicting oil price movements (Herawati and Djunaidy, 2014). This research has illustrated that in essence, between the models of the ARIMA and the Empirical Decomposition, that both can perform the oil price forecasting against current world oil price. However, the Empirical Decomposition model has a function that is more appropriate and suitable for long-term forecasting and it also has a better precision of forecasting than the ARIMA model which is only good and reliable for forecasting short term data

The results obtained have theoretical implications and assessment of the degree of accuracy based on the MAPE as it had illustrated the value of accuracy/error in assessing the overall basic forecasting model. The determination to seek the best method for oil price forecasting can be done by calculating the value of the MSE and the MAPE, which is a technique of testing the error (confusion) of each forecasting method used. The forecasting method with the value of the MSE and the smallest MAPE is the best method and it should be used to conduct studies or to analyse forecasting results (Sungkawa \& Megasari, 2011).

Future research may be conducted to compare the results of this research with other methods in predicting black gold price such as the ARCH/GARCH method of Markov Switching. Another statistical test suggested for assessing the accuracy of forecasting model is to not only rely on the MAPE test.

\section{Conclusions}

This study uses the Empirical Decomposition and ARIMA to predict world oil price. Two models in conducting Empirical Decomposition method, which are Multiplicative model and Additives model were used. The results proved that the Additive model have a smaller error than the Multiplicative model. In applying the ARIMA method, data were analyzed further by using the Autocorrelation Function and Partial Autocorrelation Function and three models of the ARIMA i.e. ARIMA $(0,1,1)$, ARIMA $(1,1,0)$, and ARIMA $(1,1,1)$. Results show that the ARIMA $(0,1,1)$ model produced the smallest error of the MAPE.

This research proves that the determination to use the appropriate model to predict world oil also known as black gold prices depends on the nature of the data. If the data were nonlinear and non-stationary, it would be better to use the Empirical Decomposition method instead of using the ARIMA method. The results of this research further considers the Empirical Decomposition to be a better and more precise model for predicting world oil price (WTI and Brent). In the comparison of the values of the MAPE between the two models, it was noted that the Empirical Decomposition method had a lower error value. Thus, this research proves that the prediction of through the ARIMA method is for flat price (constant) and this is due to the nature of the ARIMA 
data and world oil price itself. Another reason is that the world oil price prediction for long-range accuracy produced by the ARIMA was less precise.

\section{References}

Al Kharis, N. M. (2014). Analisis peramalan pendaftaran siswa baru menggunakan metode seasonal arima dan metode dekomposisi: studi kasus lembaga bimbingan belajar SSC Bintaro.

Bashiri Behmiri, N., \& Pires Manso, J. R. (2013). Crude Oil Price Forecasting Techniques: A Comprehensive Review of Literature.

Bloomberg (2016, April 1st). Bloomberg Market Data: Energy. Retrieved from https://www.bloomberg.com/quote/CL1:COM

Hendranata, A. (2003). ARIMA (Autoregressive Moving Average), Financial Management Public Sector-1993.

Herawati and Djunaidy. (2014). Crude oil price Forecasting using a combination of Empirical Mode Decomposition method of Ensemble (EEMD) and Neural Networks. SimanteC scientific journal vol. 4, no. 1 June 2014.

Horngen, C. T., Flat, S M, \& Rajan, M. V. (2012). Cost Accounting, $14^{\text {th }}$ Edition. United States. Pearson.

Loukazevits, A. (2011). The Short Term Forecasting of Crude Oil Prices - An Agent Based Perspective. Thesis MSc Economics \& Business Erasmus University of Rotterdam.

Muhammad, N. (2014). The analysis of New Students Enrollment Forecasting method using Seasonal ARIMA and the decomposition Method. Jakarta: Thesis Studies Program of the Faculty of science and technology the University of Islamic State.

Muharam \& Nurafni. (2008). An analysis of the influence of the exchange rate of the Rupiah against the American Dollar and Dow Jones Index against the JCI. Maksi Journal. The Faculty of Economics. Diponegoro University.

Ross, S. A., Westerfield, R. W., Jordan, B. D., LIM, Young Sain, Joseph, and Tan, Ruth. (2012). Fundamentals of Corporate Finance. Singapore. McGraw-Hill Education (Asia)

Sharma, Namit. (1998). Forecasting Oil Price Volatility. Master of Arts thesis in Economics, Virginia Polytechnic Institute and State University.

Storm, B. \& Pescatori. (2014). Oil Price Volatility and the Role of Speculation. IMF Working Paper 14/218

Subagyo, P. (1986). Forecasting concept and application. Yogyakarta: Gadjah Mada University BPPE.

Sungkawa and Megasari. (2011). The application of the measure of the accuracy of forecasted value Data time series forecasting Model Selection in the Sales Volume of PT Satriamandiri Citramulia. ComTech vol. 2 No. 2. Binus University.

Witjaksono, A. (2010). The analysis of the influence of the SBI interest rate, world oil prices. The World Gold price Rupiah exchange rate, the Nikkei 225 Index, and the Dow Jones against the JCI period 2000-2009. Semarang. Thesis. University of Diponegoro.

World Bank. (2015). The Great Plunge in Oil Prices: Causes, Consequences, and Policy Responses. Policy Research Notes. March 2015. PRN/15/01 